\title{
Mapping the Aspergillus niger metabolite biomarkers for in situ and early evaluation of table grapes contamination
}

\section{João Raul Belinato}

State University of Campinas: Universidade Estadual de Campinas

\section{Carina Pedrosa Costa}

Universidade de Aveiro

\section{Adelaide Almeida}

Universidade de Aveiro

\section{Silvia Rocha}

Universidade de Aveiro

Fabio Augusto ( $\square$ augusto@iqm.unicamp.br)

University of Campinas https://orcid.org/0000-0002-4673-0231

\section{Research Article}

Keywords: Aspergillus niger, food contamination, GC×GC, metabolites, HS-SPME

Posted Date: June 23rd, 2021

DOI: https://doi.org/10.21203/rs.3.rs-650006/v1

License: (c) (i) This work is licensed under a Creative Commons Attribution 4.0 International License. Read Full License

Version of Record: A version of this preprint was published at Foods on November 19th, 2021. See the published version at https://doi.org/10.3390/foods10112870. 


\section{Abstract}

Aspergillus niger volatilome was recently explored using advanced gas chromatography tools tandem with multivariate analysis, which allowed to propose a molecular biomarker pattern for this fungus. A. niger is a ubiquitous fungus responsible for food contamination, being reported as one of the main agents of the black mold disease, a serious post-harvest pathology of table grapes. In this work the metabolite pattern already proposed was tested in three different conditions, i.e., by using : (i) 1 day of growth time for $A$. niger cultures; (ii) 1 day of growth time through $A$. niger cultures obtained from previously contaminated grapes and iii) in situ SPME approach directly on previously contaminated table grapes with $A$. niger. Supervised multivariate analysis was performed which revealed that after 1 day of inoculation it was possible to detect the $A$. niger biomarkers, which allows to infer its presence. Furthermore, the follow-up of this set of metabolites showed that they can be employed to confirm the presence of the pathogen in two varieties of table grapes. The results obtained confirm the potential applicability of the pattern of $A$. niger biomarkers to early detect the fungi (after 1 day of contamination) and also may be further explored for access food susceptibility to fungi contamination, based on a direct analysis of food item and taking advantage of the high sensitivity of the GC×GC-ToFMS.

\section{Introduction}

Fungal contamination plays a major role in food spoilage and represents a problem which can result in huge economic losses, deterioration of food quality, reduction in nutrients availability, and contamination with compounds with high potential toxicity, such as mycotoxins(Finger et al. 2019). Mycotoxins are secondary metabolites produced by fungi that have adverse health effects on humans, animals, and crops. In this sense, prevention and control of these toxigenic fungi and mycotoxins in agricultural commodities have been priority objectives in food quality and safety (Bazioli et al. 2019; Gómez et al. 2019; Sun et al. 2020). Among different classes of food which are susceptible to fungal infection, the table grapes are very common case due to their thin pericarp and succulent flesh. Thus, grapes can be easily contaminated with filamentous fungi in different steps across their production chain and for this reason, the quality control of table grapes must be very strict and effective (Li et al. 2017; Freire et al. 2018a).

Some of the most relevant species related to the fungal infection of grapes are members of the genus Aspergillus (Freire et al. 2018a). Aspergillus niger is one of the main species responsible for contamination in grapes and derived products, promoting serious economic losses, being the distribution of black aspergilli in table grapes reported worldwide (Cano et al. 2015; Freire et al. 2020). The production of mycotoxins by $A$. niger is very known but the contribution to mycotoxin content in foodstuffs as well as the differences in production ability among species are controversial topics. Ochratoxin $A$ is one of the metabolites usually associated to contamination by A. niger (Abarca et al. 2019; Dachery et al. 2019; Gómez et al. 2019; Santos-Ciscon et al. 2019), including in grapes (Freire et al. 2018b, 2020). However, as it is not specific for this species and therefore it cannot be used as a unambiguous biomarker. On the other hand, recent studies reported a set of metabolites that may be assigned as a A. niger biomarkers (Costa et al. 2016; Gil-Serna et al. 2019; Schueuermann et al. 2019). These reported metabolites are distributed in 
different chemical families, such as aldehydes, ethers, alcohols, esters, ketones, hydrocarbons and terpenic compounds. Metabolic pathways such as amino acid metabolism, biosynthesis and metabolism of fatty acids, degradation of aromatic compounds, mono and sesquiterpenoid synthesis and carotenoid cleavage are found to be related to these set of compounds (Costa et al. 2016). Nevertheless, deeper studies of these metabolites production specifically for $A$. niger are still not completely explored (Akhtar et al. 2015; Costa et al. 2016).

Considering the importance of early diagnosis in food authentication and contamination, metabolomics enables the development of rapid and highly accurate molecular methods for the identification of the species. (Schloter et al. 1995; Järvinen et al. 2009; Xanthopoulou et al. 2018, 2019; Erban et al. 2019; Santos-Ciscon et al. 2019; Wang et al. 2019; Zhang et al. 2020; Fang et al. 2021). Microbial metabolomics represents a holistic approach for comprehensive monitoring of metabolites directly linked to cellular metabolism, providing an accurate snapshot of the microorganism metabolic profile and can be potentially useful for early detection (Fialho et al. 2010; Martins et al. 2017; de Souza et al. 2018a, b; Baptista et al. 2019). Untargeted microbial metabolomic approaches using mass spectrometry or mass spectroscopybased analytical platforms have become extremely important in the last few years (Cubero-Leon et al. 2014; Schueuermann et al. 2019). Although it is very informative the whole metabolome studies can provide a huge volume of data. When it comes to detection of food contamination only a partial and significant fraction of the metabolic profile is useful and desirable in order to detect the contaminant (Costa et al. 2016; Schueuermann et al. 2019). However, access to properly and interpretable data from microbe's metabolite profiles can be a real challenge due to the complexity of these samples. Therefore the use of high throughput and high sensitive analytical tools like comprehensive two dimensional gas chromatography $(\mathrm{GC} \times \mathrm{GC})$ has been used in order to explore and extract useful data from microbial metabolome (Alves et al. 2015; Mousavi et al. 2016; Cardoso et al. 2017; Rees et al. 2017; de Souza et al. 2018b; Matos et al. 2019; Fonseca et al. 2020; Martins et al. 2020; Fang et al. 2021). GC×GC provides higher sensitivity and resolution when compared to conventional one-dimensional gas chromatography (1D-GC), which fulfils the requirements for the analysis of complex biological samples. Also, GC×GC combined with time-of-flight mass spectrometry (ToFMS) increases sensitivity and detectability providing reliable identification of metabolites based on retention rates and mass spectra (de Souza et al. 2018c; Parastar et al. 2018; Carriço et al. 2020).

\section{Materials And Methods}

\subsection{Fungal strains and culture growth conditions}

The three fungal strains used in this study - Aspergillus niger (GenBank accession number KT964850), Penicillium chrysogenum (GenBank accession number KT799549) and Candida albicans (GenBank accession number SC5314) - were obtained from the Department of Biology, University of Aveiro, Portugal. Fresh cultures were prepared by inoculation on Yeast Glucose Chloramphenicol Agar $\left(\mathrm{YGC}_{\mathrm{A}}-20 \mathrm{~g} \mathrm{~L}-1 \mathrm{D}\right.$ -

glucose, $5 \mathrm{~g} \mathrm{~L}^{-1}$ yeast extract, $0.1 \mathrm{~g} \mathrm{~L}^{-1}$ chloramphenicol and $18 \mathrm{~g} \mathrm{~L}^{-1}$ agar; Liofilchem $\circledast$, Italy). 
The first experiment was conducted following the same protocol already published for the three fungal strains (Costa et al. 2016) and adapted in the current study for one day of growth after the inoculation as the workflow presented in Fig. 1-(a). Five plates were prepared with solid $\mathrm{YGC}_{\mathrm{A}}$ for each assay, where the three fungi were inoculated separately. All essays were performed in triplicate. Each experiment was repeated for 7 days in order to provide replicates at different times (i.e., three strains with 1-day growth, repeated for 7 days). For each assay, the sampling was performed by adding $10 \mathrm{~mL}$ of Ringer solution (Merck Millipore) per plate (5 plates per assay) to collect the cellular content of each sample. After that, 50 $\mathrm{mL}$ of the suspension were collected from each assay, an aliquot of $25 \mathrm{~mL}$ was collected to volatile metabolites profiling and other aliquot of $25 \mathrm{~mL}$ for the determination of cell concentration. The cell concentration was expressed as colony-forming units per milliliter $\left(\mathrm{CFU} \mathrm{mL}{ }^{-1}\right)$. The homogenized suspension was serially diluted in Ringer solution and aliquots of $100 \mu \mathrm{L}$ were spread on $\mathrm{YGC}_{\mathrm{A}}(5$ replicates per dilution). These results were employed to normalize the total areas of each chemical feature detected, therefore allowing the determination of specific metabolite production per cell. Finally, to assess general distinction based on metabolomics data, $P$. chrysogenum and $C$. albicans were also plated onto $\mathrm{YGC}_{\mathrm{A}}$ at $25^{\circ} \mathrm{C}$ also performing 5 plates for each assay under study (in a total of 15 plates per condition corresponding to 3 independents assays) and the same procedure which for $A$. niger samples in solid media mentioned above was applied. Penicillium chrysogenum was chosen to compare two filamentous fungi, though from different species, and Candida albicans was selected for its importance among immunocompromised patients within clinical setting.

\subsection{Grapes contamination protocol}

Red globe and Dominga table grapes (Vitis vinifera) in the commercial mature stage were obtained at the local market in Aveiro, Portugal. The grapes were washed, superficially disinfected with $0.2 \%(\mathrm{v} / \mathrm{v})$ sodium hypochlorite for $3 \mathrm{~min}$ and rinsed in distilled water to eliminate the residual sodium hypochlorite after being removed from the stems. After drying, the fruits were wounded in a $2 \mathrm{~mm}$ depth and $10 \mu \mathrm{L}$ of an A. niger conidial suspension $\left(1 \times 10^{5}\right.$ conidia/mL) was inoculated in the wounded area. Inoculated fruits were kept in the growth chamber under controlled temperature and humidity for seven days until the sporulation stage.

\subsection{Profiling headspace volatile metabolites by HS-SPME- GCXGC-TOFMS}

\subsubsection{Fungal cultures}

The HS-SPME and GC×GC-ToFMS experimental parameters were adapted from a previous study (Costa et al. 2016) and following the procedure presented in Fig. 1-(a). After incubation, $25 \mathrm{~mL}$ of the suspension mentioned in the previous Sect. 2.1, was centrifuged at $10.000 \mathrm{rpm}$, at $4^{\circ} \mathrm{C}$ for $15 \mathrm{~min}$ (Centrifuge Beckman AVANTI). Sequentially, $20 \mathrm{~mL}$ of supernatant was transferred into a $60 \mathrm{~mL}$ glass vial containing $4 \mathrm{~g}$ of $\mathrm{NaCl}$ ( $\geq 99.5 \%$, Sigma-Aldrich) and a stirring bar via syringe with $0.20 \mu \mathrm{m}$ filter. The vials were sealed with a silicone/polytetrafluoroethylene septum and an aluminum cap (Chromacol Ltd., Herts, UK). All the samples were stored at $-80^{\circ} \mathrm{C}$ until analysis. The SPME extraction was carried out using a 50/30 $\mu \mathrm{m}$ 
divinylbenzene/carboxen ${ }^{\text {TM }} /$ polydimethylsiloxane StableFlex ${ }^{\text {TM }}$ SPME fibre (DVB/CAR/PDMS). For HS-SPME protocol the vials were placed in a thermostatic water bath and headspace extraction was performed for 30 min, at $50^{\circ} \mathrm{C}$, and under continuous agitation at $350 \mathrm{rpm}$. Three independent aliquots were analyzed for each sample under study, at each day of growth, for seven consecutive days.

SPME fiber was manually introduced into the GC×GC-ToFMS injector and exposed for thermal desorption into heated inlet at $250^{\circ} \mathrm{C}$. The inlet was lined with a $0.75 \mathrm{~mm}$ I.D. splitless glass liner and splitless injections mode were used (30 seconds). The LECO Pegasus 4D (LECO, St. Joseph, MI, USA) GC×GCToFMS system was comprised by an Agilent GC 7890A gas chromatograph (Agilent Technologies, Inc., Wilmington, DE), with a dual-stage jet cryogenic modulator (licensed from Zoex) and a secondary oven, as well as mass spectrometer equipped with a ToF analyzer. An Equity- 5 column $(30 \mathrm{~m} \times 0.32 \mathrm{~mm}$ I.D., 0.25 $\mu \mathrm{m}$ film thickness, Supelco, Inc., Bellefonte, PA, USA) and a DB-FFAP column $(0.79 \mathrm{~m} \times 0.25 \mathrm{~mm}$ I.D., 0.25 $\mu \mathrm{m}$ film thickness, J\&W Scientific Inc., Folsom, CA, USA) were used for first ( $\left.{ }^{1} \mathrm{D}\right)$ and second ( $\left.{ }^{2} \mathrm{D}\right)$ dimensions, respectively. Helium was employed as carrier gas at a constant flow rate of $2.50 \mathrm{~mL} \mathrm{~min}^{-1}$. The following temperature programs were used: the primary oven temperature was ranged from $40^{\circ} \mathrm{C}(1$ $\min )$ to $140^{\circ} \mathrm{C}$ at $10^{\circ} \mathrm{C} \mathrm{min}-1$, and then to $200^{\circ} \mathrm{C}(1 \mathrm{~min})$ at $7^{\circ} \mathrm{C} \mathrm{min}^{-1}$. The secondary oven temperature program was $15^{\circ} \mathrm{C}$ offset above the primary oven. Both the MS transfer line and MS source temperatures were $250^{\circ} \mathrm{C}$. The modulation period was 5 seconds, keeping the modulator at $20^{\circ} \mathrm{C}$ offset above the primary oven, with hot and cold pulses by periods of 0.80 and 1.70 seconds, respectively. The ToF analyzer was operated at a spectrum storage rate of 100 spectra $\mathrm{s}^{-1}$, with mass spectrometer running in the EI mode at $70 \mathrm{eV}$ and detector voltage of $-1480 \mathrm{~V}$, using a $\mathrm{m} / \mathrm{z}$ range of $35-300$. The software ChromaTOF® (LECO) was used to process the total ion chromatograms at the signal-to-noise threshold of 200 . For identification purposes, the mass spectrum and retention times ( ${ }^{1} D$ and $\left.{ }^{2} D\right)$ of the analytes were compared with standards, when available. Also, the identification process was done by comparing the mass spectrum of each peak with existing ones in mass spectral libraries, which included an in-house library of standards and two commercial databases (Wiley 275 and US National Institute of Science and Technology (NIST) V. 2.0 - Mainlib and Replib). Moreover, additional information like linear retention index (RI) value was considered, which was experimentally determined considering the van den Dool and Kratz RI indexes(van Den Dool and Dec. Kratz 1963). For this purpose, $C_{8}-C_{20}$ n-alkanes series (the solvent $n$-hexane was used as $\mathrm{C}_{6}$ standard) was used for RI determination comparing these values with reported ones in existing literature for chromatographic columns similar to ${ }^{1} \mathrm{D}$ column (Table 1). The Deconvoluted Total Ion Current GC×GC area data were used as an approach to estimate the relative content of each metabolite under study.

\subsubsection{Contaminated table grapes}

The contaminated grapes as described in the Sect. 2.2 were analyzed using two strategies. The first protocol involved spreading the fungus spores obtained from the contaminated grapes after 7 days of growth into Petri dishes containing $\mathrm{YGC}_{\mathrm{A}}$ and standardizing the use of two grapes per dish (Fig. 1-(b). After that, the samples were submitted to the same growth conditions and extraction procedures as following the Fig. 1-(a) and described before. In this case five replicates for both varieties of grapes were carried out 
due to confirm the metabolite profile obtained from them. The second approach employed the in situ HSSPME strategy to extract and analyze the metabolites produced by the fungus directly in the fruits. In this case, ten contaminated grapes were transferred to adapted flasks which enables them to be hermetically closed and a septum for the SPME fiber introduction. Thus, the in-situ experiment was designed to analyze the volatile organic compounds produced by the fungus after 24 hours of inoculation, fourth and seventh days. For each condition, three independent samples were prepared. In both varieties, Red Globe and Dominga there was no cross contamination since the inoculation of the fungus was performed in sterilized environment. In cases where there were contamination by other microorganisms, these were discarded.

\subsection{Statistical analysis}

This study consists of two sets of data (Tables S1 and S2). The first data set matrix consists of 54 independent observations, 30 of which refer to 3 fungal species in different growth times ( 3 and 5 days); 9 referring to a data set in which only the fungus $A$. niger was evaluated in growth times of 3 and 1 day and 15 addressed to the data set obtained in order to confirm the feasibility of the reduction for the detection time of one day, all replicates referring to $A$. niger. In addition, there are ten independent observations of the profile of metabolites from $A$. nigerisolated from grapes (Table S1). The second set of data was obtained from the profile of volatile organic compounds obtained for the same fungus directly in contaminated grapes, using an in situ-SPME approach (Table S2).

All the data set was firstly normalized by colony forming unit per milliliter (CFU mL ${ }^{-1}$ ) due to provide an accurate idea of the metabolite's concentration per cell. Initially, the set of 44 metabolites detected in a previous study was used to extract information about the new conditions employed (1 day of growth). These metabolites were defined as $A$. niger molecular biomarkers pattern, and an exploratory test was done to evaluate its potential in fungi distinction. Before the multivariate analysis, the peak areas of the 44 selected analytes were measured for the $A$. niger samples and also for the $C$. albicans and $P$. chrysogenum strains. In order to provide a comprehensive study and a higher number of samples, archival data previously collected in similar experiments in our laboratory were included in the evaluated models enabling a comparison among all the systems in different growth times and also different periods of experiments $(2014,2016,2018)$. The whole data set employed in this study can be found in Supplementary Information (Table S.1 and S.2). Regarding the multivariate analysis, PCA and PLS-DA strategies were employed using MetaboAnalyst 4.0. The peak areas were previously normalized by the total area, meancentered and autoscaled, which is a data pre-treatment process that gives to variables the same weight. The classification model was statistically validated using Leave-one-out cross-validation (LOOCV) which provides the analysis of accuracy, $\mathrm{R}^{2}$ (quality-of-fit) and $\mathrm{Q}^{2}$ (quality-of-prediction). Model robustness was assessed using a permutation test (1000 permutations).

\section{Results And Discussion}

3.1. Evaluating the potential of A. niger molecular biomarkers pattern for strains distinction at 1-day of cultures growth 
The initial experiments were performed based on a previous study which includes the evaluation of the volatile profile of the fungus $A$. niger in comparison with other species and under different growth conditions (Costa et al. 2016). Thus, using previously optimized method and other growth conditions, the growth time was reduced for one day in order to minimize the detection time of the fungus in relation to the previous method that spends 3 and 5 days. All the experiments were performed by using the 44 molecular biomarker pattern previous reported (Costa et al. 2016). For this purpose, the analyses were performed on 7 different days and in triplicate to validate the new suggested methodology. The 44 metabolites set was chosen since they were identified in all the conditions studied for $A$. niger and, therefore, it was defined as a standard of molecular biomarkers for this microorganism. The data set is quite variable in relation to the chemical classes, being hydrocarbons, including aliphatic and aromatic (31.8\%), alcohols $(22.7 \%)$, aldehydes (20.5\%), ketones (11.4\%), esters (6.8\%), terpenic compounds (4.6\%) and norisoprenoids $(2.3 \%)$ (Costa et al. 2016). Table 1 presents the list of the 44 metabolites reported as A. niger molecular biomarkers pattern and determined by HS-SPME/GC×GCToFMS in the samples under study.

Table 1. List of the 44 metabolites reported as $A$. niger molecular biomarkers pattern (Costa et al. 2016) and determined by HS-SPME/GC×GCToFMS in the samples under study. 


\begin{tabular}{|c|c|c|c|c|c|c|c|c|}
\hline $\begin{array}{c}\text { Peak } \\
\text { number }\end{array}$ & $1_{t_{\mathrm{R}}}^{\mathrm{a}}(\mathrm{s})$ & ${ }^{2} t_{\mathrm{R}}^{\mathrm{a}}(\mathrm{s})$ & Metabolite & $\begin{array}{c}\text { CAS } \\
\text { number }\end{array}$ & Formula & $\begin{array}{c}\text { MSI } \\
\text { level }^{\mathrm{b}}\end{array}$ & $\mathrm{RI}_{\text {Calc }}{ }^{\mathrm{c}}$ & $\mathrm{RI}_{\mathrm{Lit}}{ }^{\mathrm{d}}$ \\
\hline 1 & 115 & 0.910 & 1-Butanol & $71-36-3$ & $\mathrm{C}_{4} \mathrm{H}_{10} \mathrm{O}$ & 1 & 644 & $\begin{array}{c}655 \text { (Xu et al. } \\
2003)\end{array}$ \\
\hline 2 & 150 & 1.160 & 3-Methyl-1-butanol & $\begin{array}{c}123-51- \\
3\end{array}$ & $\mathrm{C}_{5} \mathrm{H}_{12} \mathrm{O}$ & 1 & 718 & $\begin{array}{c}706 \text { (Rocha et al. } \\
\text { 2013) }\end{array}$ \\
\hline 3 & 255 & 1.140 & 1-Hexanol & $\begin{array}{c}111-27- \\
3\end{array}$ & $\mathrm{C}_{6} \mathrm{H}_{14} \mathrm{O}$ & 1 & 878 & $\begin{array}{c}877 \text { (Rocha et al. } \\
\text { 2013) }\end{array}$ \\
\hline 4 & 345 & 1.100 & 1-Heptanol & $\begin{array}{c}111-70- \\
6\end{array}$ & $\mathrm{C}_{7} \mathrm{H}_{16} \mathrm{O}$ & 2 & 975 & $\begin{array}{l}\text { 974(Salvador et } \\
\text { al. 2013) }\end{array}$ \\
\hline 5 & 350 & 1.050 & 1-Octen-3-ol & $\begin{array}{c}3391- \\
86-4\end{array}$ & $\mathrm{C}_{8} \mathrm{H}_{16} \mathrm{O}$ & 1 & 980 & $\begin{array}{c}992 \text { (Silva et al. } \\
\text { 2010) }\end{array}$ \\
\hline 6 & 365 & 1.270 & 3-Octanol & $\begin{array}{l}589-98- \\
0\end{array}$ & $\mathrm{C}_{8} \mathrm{H}_{18} \mathrm{O}$ & 1 & 996 & $\begin{array}{c}996 \text { (Oliveira et al. } \\
\text { 2006) }\end{array}$ \\
\hline 7 & 395 & 0.990 & 2-Ethyl-1-hexanol & $\begin{array}{c}104-76- \\
7\end{array}$ & $\mathrm{C}_{8} \mathrm{H}_{18} \mathrm{O}$ & 2 & 1029 & $\begin{array}{c}1038 \text { (Silva et al. } \\
\text { 2010) }\end{array}$ \\
\hline 8 & 440 & 1.030 & 1-Octanol & $\begin{array}{l}111-87- \\
5\end{array}$ & $\mathrm{C}_{9} \mathrm{H}_{18} \mathrm{O}_{2}$ & 1 & 1079 & $\begin{array}{c}1079 \text { (Silva et al. } \\
\text { 2010) }\end{array}$ \\
\hline 9 & 475 & 3.030 & 2-Phenylethanol & $60-12-8$ & $\mathrm{C}_{8} \mathrm{H}_{10} \mathrm{O}$ & 1 & 1120 & $\begin{array}{c}1107 \text { (Weldegergis } \\
\text { et al. 2011) }\end{array}$ \\
\hline 10 & 805 & 2.060 & $\begin{array}{l}\text { 2,4-bis }(1,1- \\
\text { Dimethylethyl)phenol }\end{array}$ & $96-76-4$ & $\mathrm{C}_{14} \mathrm{H}_{22} \mathrm{O}$ & 2 & 1514 & $\begin{array}{c}1513 \text { (Zhao et al. } \\
\text { 2006) }\end{array}$ \\
\hline 11 & 110 & 0.460 & 3-Methylbutanal & $\begin{array}{l}590-86- \\
3\end{array}$ & $\mathrm{C}_{5} \mathrm{H}_{10} \mathrm{O}$ & 2 & 633 & $\begin{array}{l}628 \text { (Loureiro et } \\
\text { al. 2014) }\end{array}$ \\
\hline 12 & 190 & 0.590 & Hexanal & $66-25-1$ & $\mathrm{C}_{6} \mathrm{H}_{12} \mathrm{O}$ & 1 & 801 & $\begin{array}{c}800 \text { (Rocha et al. } \\
\text { 2012) }\end{array}$ \\
\hline 13 & 275 & 0.620 & Heptanal & $\begin{array}{c}111-71- \\
7\end{array}$ & $\mathrm{C}_{7} \mathrm{H}_{14} \mathrm{O}$ & 1 & 901 & $\begin{array}{c}903 \text { (Rocha et al. } \\
\text { 2012) }\end{array}$ \\
\hline 14 & 465 & 0.630 & Nonanal & $\begin{array}{c}124-19- \\
6\end{array}$ & $\mathrm{C}_{9} \mathrm{H}_{18} \mathrm{O}$ & 1 & 1106 & $\begin{array}{c}1106 \text { (Rocha et al. } \\
\text { 2013) }\end{array}$ \\
\hline 15 & 555 & 0.630 & Decanal & $\begin{array}{c}112-31- \\
2\end{array}$ & $\mathrm{C}_{10} \mathrm{H}_{20} \mathrm{O}$ & 2 & 1207 & $\begin{array}{c}1206 \text { (Rocha et al. } \\
\text { 2012) }\end{array}$ \\
\hline 16 & 685 & 0.770 & 2-Undecenal & $\begin{array}{l}2463- \\
77-6\end{array}$ & $\mathrm{C}_{11} \mathrm{H}_{20} \mathrm{O}$ & 2 & 1364 & $\begin{array}{c}1369 \text { (Liu et al. } \\
\text { 2007) }\end{array}$ \\
\hline 17 & 720 & 0.650 & Dodecanal & $\begin{array}{c}112-54- \\
9\end{array}$ & $\mathrm{C}_{12} \mathrm{H}_{24} \mathrm{O}$ & 2 & 1407 & $\begin{array}{c}1406 \text { (Rocha et al. } \\
\text { 2012) }\end{array}$ \\
\hline 18 & 335 & 1.550 & Benzaldehyde & $\begin{array}{c}100-52- \\
7\end{array}$ & $\mathrm{C}_{7} \mathrm{H}_{6} \mathrm{O}$ & 1 & 965 & $\begin{array}{l}954 \text { (Caldeira et } \\
\text { al. 2011) }\end{array}$ \\
\hline 19 & 410 & 1.620 & Benzeneacetaldehyde & $\begin{array}{c}122-78- \\
1\end{array}$ & $\mathrm{C}_{8} \mathrm{H}_{8} \mathrm{O}$ & 1 & 1046 & $\begin{array}{c}1049 \text { (Xu et al. } \\
2003)\end{array}$ \\
\hline 20 & 135 & 0.530 & $\begin{array}{l}\text { Methyl 2- } \\
\text { methylpropenoate }\end{array}$ & $80-62-6$ & $\mathrm{C}_{5} \mathrm{H}_{8} \mathrm{O}_{2}$ & 2 & 685 & $\begin{array}{c}710 \text { (Xu et al. } \\
2003)\end{array}$ \\
\hline 21 & 695 & 0.920 & $\begin{array}{l}\text { 3-Hydroxy-2,4,4- } \\
\text { trimethylpentyl } \\
\text { methylpropanoate }\end{array}$ & $\begin{array}{c}74367- \\
34-3\end{array}$ & $\mathrm{C}_{12} \mathrm{H}_{24} \mathrm{O}_{3}$ & 2 & 1376 & $\begin{array}{c}1376 \text { (Costa et al. } \\
\text { 2016) }\end{array}$ \\
\hline 22 & 545 & 1.050 & 2-Phenylethylacetate & $\begin{array}{c}103-45- \\
7\end{array}$ & $\mathrm{C}_{10} \mathrm{H}_{12} \mathrm{O}_{2}$ & 2 & 1196 & $\begin{array}{c}1196 \text { (Costa et al. } \\
\text { 2016) }\end{array}$ \\
\hline 23 & 880 & 0.490 & Hexadecane & $\begin{array}{c}544-76- \\
3\end{array}$ & $\mathrm{C}_{16} \mathrm{H}_{34}$ & 1 & 1601 & $\begin{array}{c}1600 \text { (Rocha et al. } \\
\text { 2012) }\end{array}$ \\
\hline 24 & 965 & 0.430 & Heptadecane & $\begin{array}{c}629-78- \\
7\end{array}$ & $\mathrm{C}_{17} \mathrm{H}_{36}$ & 1 & 1701 & $\begin{array}{c}1700 \text { (Rocha et al. } \\
\text { 2012) }\end{array}$ \\
\hline 25 & 115 & 0.460 & Benzene & $71-43-2$ & $\mathrm{C}_{6} \mathrm{H}_{6}$ & 1 & 643 & $\begin{array}{c}643 \text { (Costa et al. } \\
\text { 2016) }\end{array}$ \\
\hline 26 & 170 & 0.540 & Toluene & 108-88- & $\mathrm{C}_{7} \mathrm{H}_{8}$ & 1 & 759 & 771 (Xu et al. \\
\hline
\end{tabular}




\begin{tabular}{|c|c|c|c|c|c|c|c|c|}
\hline & & & & 3 & & & & 2003) \\
\hline 27 & 250 & 0.590 & 1,3-Dimethylbenzene & $\begin{array}{c}108-38- \\
3\end{array}$ & $\mathrm{C}_{8} \mathrm{H}_{10}$ & 2 & 871 & $\begin{array}{c}871 \text { (Costa et al. } \\
\text { 2016) }\end{array}$ \\
\hline 28 & 270 & 0.640 & 1,2-Dimethylbenzene & $95-47-6$ & $\mathrm{C}_{8} \mathrm{H}_{10}$ & 2 & 901 & $\begin{array}{c}900 \text { (Rocha et al. } \\
\text { 2013) }\end{array}$ \\
\hline 29 & 325 & 0.580 & Propylbenzene & $\begin{array}{c}103-65- \\
1\end{array}$ & $\mathrm{C}_{9} \mathrm{H}_{12}$ & 2 & 953 & $\begin{array}{c}959 \text { (Xu et al. } \\
2003)\end{array}$ \\
\hline 30 & 335 & 0.590 & $\begin{array}{l}\text { 1-Ethyl-4- } \\
\text { methylbenzene }\end{array}$ & $\begin{array}{c}622-96- \\
8\end{array}$ & $\mathrm{C}_{9} \mathrm{H}_{12}$ & 2 & 964 & $\begin{array}{c}970 \text { (Xu et al. } \\
2003)\end{array}$ \\
\hline 31 & 365 & 0.640 & $\begin{array}{l}\text { 1,3,5- } \\
\text { Trimethylbenzene }\end{array}$ & $\begin{array}{c}108-67- \\
8\end{array}$ & $\mathrm{C}_{9} \mathrm{H}_{12}$ & 2 & 995 & $\begin{array}{c}974 \text { (Xu et al. } \\
\text { 2003) }\end{array}$ \\
\hline 32 & 390 & 0.580 & $\begin{array}{l}\text { 1-Methyl-2-(1- } \\
\text { methylethyl)benzene }\end{array}$ & $\begin{array}{c}527-84- \\
4\end{array}$ & $\mathrm{C}_{10} \mathrm{H}_{14}$ & 2 & 1023 & $\begin{array}{c}1023 \text { (Costa et al. } \\
\text { 2016) }\end{array}$ \\
\hline 33 & 390 & 0.690 & $\begin{array}{l}1,2,3- \\
\text { Trimethylbenzene }\end{array}$ & $\begin{array}{c}526-73- \\
8\end{array}$ & $\mathrm{C}_{9} \mathrm{H}_{12}$ & 1 & 1023 & $\begin{array}{c}1023 \text { (Costa et al. } \\
\text { 2016) }\end{array}$ \\
\hline 34 & 425 & 0.610 & $\begin{array}{l}\text { 2-Ethyl-1,4- } \\
\text { dimethylbenzene }\end{array}$ & $\begin{array}{c}1758- \\
88-9\end{array}$ & $\mathrm{C}_{10} \mathrm{H}_{14}$ & 2 & 1062 & $\begin{array}{c}1062 \text { (Costa et al. } \\
\text { 2016) }\end{array}$ \\
\hline 35 & 700 & 1.270 & Biphenyl & $92-52-4$ & $\mathrm{C}_{12} \mathrm{H}_{10}$ & 2 & 1383 & $\begin{array}{c}1383 \text { (Costa et al. } \\
\text { 2016) }\end{array}$ \\
\hline 36 & 880 & 1.020 & $\begin{array}{l}\text { 2-Methyl-6-phenyl-1,6- } \\
\text { heptadiene }\end{array}$ & $\begin{array}{l}51708- \\
97-5\end{array}$ & $\mathrm{C}_{14} \mathrm{H}_{18}$ & 2 & 1601 & $\begin{array}{c}1601 \text { (Costa et al. } \\
\text { 2016) }\end{array}$ \\
\hline 37 & 75 & 0.390 & 2-Propanone & $67-64-1$ & $\mathrm{C}_{3} \mathrm{H}_{6} \mathrm{O}$ & 1 & 559 & $\begin{array}{c}559 \text { (Costa et al. } \\
\text { 2016) }\end{array}$ \\
\hline 38 & 265 & 0.580 & 3-Heptanone & $\begin{array}{c}106-35- \\
4\end{array}$ & $\mathrm{C}_{7} \mathrm{H}_{14} \mathrm{O}$ & 1 & 889 & $\begin{array}{c}884 \text { (Xu et al. } \\
\text { 2003) }\end{array}$ \\
\hline 39 & 355 & 0.740 & $\begin{array}{l}\text { 6-Methyl-5-hepten-2- } \\
\text { one }\end{array}$ & $\begin{array}{c}110-93- \\
0\end{array}$ & $\mathrm{C}_{8} \mathrm{H}_{14} \mathrm{O}$ & 1 & 985 & $\begin{array}{c}985 \text { (Xu et al. } \\
2003)\end{array}$ \\
\hline 40 & 495 & 0.760 & 3-Nonen-2-one & $\begin{array}{c}18402- \\
83-0\end{array}$ & $\mathrm{C}_{9} \mathrm{H}_{16} \mathrm{O}$ & 2 & 1140 & $\begin{array}{c}1140 \text { (Costa et al. } \\
\text { 2016) }\end{array}$ \\
\hline 41 & 755 & 0.800 & $\begin{array}{l}\text { 6,10-Dimethyl-5,9- } \\
\text { undecadien-2-one }\end{array}$ & $\begin{array}{l}3796- \\
70-1\end{array}$ & $\mathrm{C}_{13} \mathrm{H}_{22} \mathrm{O}$ & 2 & 1451 & $\begin{array}{c}1451 \text { (Costa et al. } \\
\text { 2016) }\end{array}$ \\
\hline 42 & 435 & 0.790 & $\begin{array}{l}\text { 2,6-Dimethyl-7-octen- } \\
\text { 2-ol }\end{array}$ & $\begin{array}{c}18479- \\
58-8\end{array}$ & $\mathrm{C}_{10} \mathrm{H}_{20} \mathrm{O}$ & 2 & 1073 & $\begin{array}{c}1073 \text { (Costa et al. } \\
\text { 2016) }\end{array}$ \\
\hline 43 & 625 & 0.630 & Endobornyl acetate & $76-49-3$ & $\mathrm{C}_{12} \mathrm{H}_{20} \mathrm{O}_{2}$ & 2 & 1289 & $\begin{array}{c}1289 \text { (Costa et al. } \\
\text { 2016) }\end{array}$ \\
\hline 44 & 780 & 0.750 & $\alpha$-Methylionone & $\begin{array}{c}127-51- \\
5 \\
\end{array}$ & $\mathrm{C}_{14} \mathrm{H}_{22} \mathrm{O}$ & 2 & 1482 & $\begin{array}{c}1482 \text { (Costa et al. } \\
\text { 2016) }\end{array}$ \\
\hline
\end{tabular}

According to Figure 2, it is possible to verify differences between the culture medium and one day of growth, highlighting the compounds (1) 1-Butanol, (9) 2-Phenylethanol, (26) Toluene, and (43) Endobornyl acetate, assigned in Table S1. For 2-Phenylethanol (Figure 2-c) the peak was identified at a mass spectral acquisition of 100 spectra/s for 1 day of growth and absent for the $\mathrm{YGC}_{\mathrm{A}}$ corroborating the fact that the indicated compounds are directly related to the presence of the microorganism. 
Therefore, the data set was submitted to evaluation using PLS-DA. This type of tool has been widely used in metabolic approaches, essentially when each of the selected classes is known. The variation of the samples can be explained by the latent variable which in statistics can be considered the variables that are not directly observed but are rather inferred (through a mathematical model) (Pan et al. 2016; Adamiak et al. 2017). The results obtained within this set (Figure 3 ) demonstrate that there is a distinction between the three classes of microorganisms studied, however, there is a great dispersion among the data for $A$. niger in the different growth times (Table S1). On the other hand, through the biplot it is possible to observe that most of the related loadings are grouped in the $A$. niger region, being a great indicator of the contribution of these metabolites as biomarkers to this system. Thus, to verify the classification model established for the data set, it was evaluated using cross-validation.

Cross-validation was performed by using a specific number of samples that are reserved for the construction of the model (training set) and another portion for testing the built model (validation set). The proper choice of cross-validation method from those available basically depends on the number of samples available for use in the training set and validation. In this case, Leave One Out Cross-Validation (LOOCV) was used for the data set in this study once the number of samples is small and it is not possible to assign a sample set to the validation set. The LOOCV consists of choosing one of the samples to compose the validation set and the remaining samples are used for the training set. A new sample is then taken to make up the validation set and the sample that was previously used for the validation set this time will make up the training set; these operations are repeated iteratively several times until all the samples have been part of the validation set at least once (Triba et al. 2015). Table 2 presents the results for the statistical parameters obtained in the model validation according to the number of main components used to describe the data.

Table 2. Statistical parameters for the evaluation of the PLS-DA model according to the number of components for the classification model.

\section{Parameters $\quad$ Latent Variable 1 Latent Variable 2 Latent Variable 3 Latent Variable 4 Latent Variable 5}

\begin{tabular}{|c|c|c|c|c|c|}
\hline Accuracy & 0.7778 & 0.7778 & 0.9815 & 1.0 & 1.0 \\
\hline $\mathrm{R}^{2}$ & 0.4548 & 0.8821 & 0.9152 & 0.9312 & 0.9557 \\
\hline $\mathrm{Q}^{2}$ & 0.2957 & 0.7888 & 0.8252 & 0.81084 & 0.8128 \\
\hline
\end{tabular}

By looking at the three components, the values of $\mathrm{R}^{2}, \mathrm{Q}^{2}$, and accuracy are $0.9152,0.8252$, and 0.9815 , respectively. However, statistical parameters $\mathrm{R}^{2}$ and $\mathrm{Q}^{2}$ are the most important diagnostic tools for evaluating the performance of the built model. The $\mathrm{R}^{2}$ parameter refers to the fitting quality of the model and it is responsible for measuring the performance considering adjusting the raw data. Thus, the values of $\mathrm{R}^{2}$ range from 0 to 1 , where 1 indicates a perfect model and 0 indicates no adjustment or modeling ( $\mathrm{Li}$ et al. 2020). The main disadvantage of parameter $R^{2}$ is that it can be adjusted to close to 1 including more terms 
to the model (in this case, latent variables), and therefore is not a sufficient indicator to assess the validity of the model. Another parameter that should also be evaluated in indicating the utility of a regression model is $Q^{2}$. This parameter is called "predictive quality" and estimates the predictive power of the model, i.e. the model's ability to predict results from unknown samples. $Q^{2}$ represents a more realistic and useful performance indicator since it reflects the final objective of modeling that refers to predictions for new experiments. Thus, $\mathrm{R}^{2}$ and $\mathrm{Q}^{2}$ have an upper limit of 1 and the validity of a model is related to the high values of $\mathrm{R}^{2}$ and $\mathrm{Q}^{2}$. In general, $\mathrm{Q}^{2}>0.5$ can be considered good and $\mathrm{Q}^{2}>0.9$ excellent. Accuracy, in general, is used to describe the proximity of a measure to a value taken as true. In classification models, accuracy represents the number of correctly predicted samples in relation to the total of samples in the test set. Always use as few components as possible in the construction of the model from which there is no significant gain in the accuracy and other parameters of the model evaluation, and this should be done by keeping the values of these parameters close to 1 and thus ensure the high predictability of the model. The use of more components than necessary results in the inclusion of unnecessary information to the model, making it over-adjusted and thus compromising its predictive ability. Thus, taking into account that it is the construction of a model based on living organisms and its metabolic productions may vary according to environmental conditions and other external factors, the values obtained by the parameters $R^{2}, Q^{2}$ and accuracy ensure the rationality of the model built for this study, being possible to use it in the prediction of new samples (Triba et al. 2015; Fan et al. 2020).

Compounds such as 2-phenylethanol, 3-octanol, 3-methyl-1-butanol are among the most important variables and have already been described in the literature as characteristic volatile metabolites of fungal species, including for $A$. niger (Costa et al. 2016; Zhao et al. 2017; Schueuermann et al. 2019). Volatile organic compounds such as geosmin, methylisoborneol, 1-octen-3-ol, 1-octen-3-one and 3-octanone have been reported as common to several fungal species and also, sensory differences between wines made with grapes contaminated with different kinds of bunch rots were already described (Schueuermann et al. 2019). In this sense, it is important to choose compounds that can be used as unique biomarkers for classes of microorganisms, as this targeted approach facilitates their identification without the use of highly complex data. Thus, statistical models can be concluded based on these metabolites to evaluate if this selection is sufficient and valid for a classification model.

\subsection{Following the A. niger molecular biomarkers pattern over 7 days}

\subsubsection{By analysis of $A$. niger cultures obtained from contaminated grapes}

Based on the previous model an application study was carried out due to detect $A$. niger in contaminated grapes. Same growth strategies, analysis and data treatment were employed, and the data obtained were tested to predict whether or not there are the samples contaminated with the pathogen. Thus, after 7 growth days the spores of $A$. niger in the grape were transferred to the petri dishes with $Y G C_{A}$ medium. For this procedure two grapes per plate were used and the experiments were performed in 5 repetitions for each grape variety. Figure 4 presents the complete data set, using the same previous model including the samples from contaminated grapes. 
According to Figure 4 the set of data obtained with the contaminated grapes is similar to the previous data obtained to construct the model as follow at the PLS-DA graph. Therefore, the fungus can be detected after only one day of infection. The interest in detecting the presence of microorganisms has been widely studied (Rees et al. 2018; Sarrocco and Vannacci 2018), with applications employed in the hospital area (Pantoja et al. 2016; Tong et al. 2017), the environment (Aquino et al. 2018) and mainly food (Cumeras et al. 2016; Schueuermann et al. 2019), including the fungus $A$. niger (Jedidi et al. 2017).. Nevertheless, the differential of this study lies in the fact that the detection of contamination by A. niger can be performed in only one day involving all the steps described above, which is quite significant when compared to traditional methods involving the isolation and identification of the fungus following microbiological protocols. Although the protocol is not an identification that can completely replace the use of molecular tools, the strategy employed can assist in the early investigation due to detection or not of the microorganisms' presence before using other approaches for accurate identification.

\subsubsection{By direct analysis of contaminated table grapes - in situ-SPME}

The followed volatile metabolite profile of the disease was evaluated through 7 days of growth by using 42 metabolites associated with $A$. niger metabolism because in this study only 42 of the total set of metabolites were identified in grapes. By employing this strategy 2-methyl-6-phenyl-1,6-heptadiene and methyl 2-methylpropenoate were not found. Although there is no clear indication regarding its absence the differences in the substrate can slightly modify the metabolite production indicating the importance of in situ studies. In situ-SPME strategy was performed using a non-invasive headspace approach. Data were equally subjected to statistical analysis using MetaboAnalyst 4.0 tool to identify a possible grouping of the investigated samples. Figure 5 shows that there was a clear separation between the samples associated with a variation in the concentration of metabolites over the days of fungal growth. In vivo SPME studies have been widely applied for food analysis since the coated surface are biocompatible and also to provide higher sensitivity and reduced analysis time (Souza-Silva et al. 2015; Zhang et al. 2016; Risticevic et al. 2020).

From the PLS-DA scores plot (Figure 5) there is a clear distinction between the grape varieties used, with the latent variable 2 (LV2) responsible for this distinction. However, the latent variable 1 (LV1) is the main responsible for explaining the data obtained $(41.1 \%)$ and it demonstrates the level of contamination by $A$. niger over the 7 days. The level of contamination is more pronounced than the difference between grape varieties. In addition, from these data it was also possible to observe that red grapes (RG) were more resistant to contamination than white grapes (Do), this is because after 4 days of contamination the metabolite profile is still quite similar to that of the first day. This fact can be explained by the high concentration of phenolic and antioxidant compounds in general present in this type of grape, ensuring it a higher resistance to contamination. A recent study demonstrated the antagonistic activity of essential oils of eight plants against strains of $A$. niger, and one of the factors highlighted by the authors was the presence of antioxidant compounds that helped to control the disease in stored wheat grains (Kumar et al. 2017; Ll et al. 2019). Fu-xiang et. al. have demonstrated that fresh grapes are rich in bioactive phenolic compounds and the concentration of these ones depends heavily on the grape varieties. The Mascot Kyoho variety (red skin) has presented the highest concentration of antioxidant compounds such as (+)- 
catechin, (-)-epicatechin, rutin, isoquercitrin and kaempferol. The phenolic compounds of grapes are mainly in skins this corroborates the results shown above, where the high content of antioxidant compounds promotes resistance to the growth of the pathogen. The effect of inhibiting the growth of $A$. niger against antioxidant enzymes has been previously studied and possibly suggest the induction of antioxidant defense response by Trichoderma bio- controller to combat oxidative burst produced by invading pathogen. (Gajera et al. 2016; LI et al. 2019).

By using the heatmap tool it is possible to identify the main metabolites associated with this distinction and infer that this variation is directly associated with the level of infection of the grapes. According to Figure 5 and Figure S1 there is some metabolites pattern associated with the high level of contamination. The biplot (Figure 4) and heatmaps (Figure S1) demonstrates the most important compounds directly related to the $A$. niger contamination are 3-octanol, 2-phenylethanol, 3-methyl-butanol and 1-octen-3ol (only for Dominga). Based on previous reported studies, all of these compounds can be associated to volatile organic compounds produced by microorganisms species (Akhtar et al. 2015; Masuo et al. 2015; de Souza et al. 2018c) even A. niger (Costa et al. 2016; Schueuermann et al. 2019). Previous studies have demonstrated the pathway for the production of 1-octanol is from glucose and fatty acids in E. coli and this compound is mainly accumulated in the culture media fraction (Akhtar et al. 2015). Furthermore, 2phenyletanol and 3-methyl-butanol compounds are very common as microorganisms' biomarkers. The production of these metabolites are associated with isoleucine/leucine and phenylalanine pathway metabolism, respectively (Hazelwood et al. 2008; Masuo et al. 2015; de Souza et al. 2018c).

Non-invasive methods such as HS-SPME is very useful in the detection and monitoring of food contamination, including the level of contamination. Recent works have demonstrated the utilization of metabolomic strategies in the detection of several microorganisms in grapes and grape juices (Costa et al. 2016; Freire et al. 2018a; Schueuermann et al. 2019). In general, the approaches utilized involve a nontarget metabolic exploration step in order to verify a pattern of compounds responsible for the contamination and from this point on, only these target compounds are monitored to verify different levels of contamination (Poole 2017; Schueuermann et al. 2019). This was also the approach initially used during this work and therefore justifies the choice of the set of metabolites investigated.

The data obtained so far demonstrate that it is possible to detect and know the level of contamination by A. niger directly in grapes using a non-invasive and rapid method. From this initial information, new statistical tools and approaches will be employed in order to explore these data in more depth and obtain important information regarding the profile of volatile metabolites and their relationship with the level of contamination of the disease (Kumar et al. 2017; Ho et al. 2020).

\section{Conclusions}

It was possible to perform the construction of an experimental model from the previously selected metabolites by reducing the growth time to one day. The model was validated employing statistical tests and the results were satisfactory taking into account we are modeling the microorganism's behavior. In addition, the model was tested to verify the presence of the microorganism A. niger in contaminated grapes 
for two varieties and proving the presence of the microorganism even with one day of detection time. Fungus detection from the set of metabolites was also used for a kinetic follow-up of the fungus growth over 7 days. Using a PLS-DA model it was possible to classify the samples by contamination level and grape variety used. Thus, the results obtained throughout the study suggest that reducing the growth time of the microorganism to one day does not affect its identification and it is extremely useful to make this type of method possible for the rapid detection of food contamination. Furthermore, the study of the variation in the metabolic profile throughout the growth showed that this approach can also be used to infer the level of contamination in grapes using a non-invasive method. Moreover, it is hoped that the methodology developed can be extended to other problems involving the detection of this microorganism, such as its detection in other foods, or even in other environments where it may be present in a way that is harmful to human health. Although this article represents a step forward in the evaluation of the applicability of the metaboloma of $A$. niger in contaminated real samples, for its further application in other particular scenarios, it is mandatory to look for other parameters, such as, limits of detection, evaluation of confounders, matrix effects and the presence of a mixture of species (co-cultures), among others.

\section{Declarations}

Acknowledgments : The authors thank the Foundation for Research Support of the State of São Paulo (Fapesp) - Process Number 2016/20547-2), The National Institute of Science and Technology in Bioanalysis (INCTBio) and Santander Bank for providing funding for this research and for scholarships. Thanks are also due to the University of Aveiro and FCT/MEC for the financial support to QOPNA (UID/QUI/00062/2019), LAQV-REQUIMTE (UIDB/50006/2020) and CESAM (UID/AMB/50017/2019) Research Units, through national funds and where applicable co-financed by the FEDER, within the PT2020 Partnership Agreement.

Conflicts of Interest: The authors declare no conflict of interest.

\section{References}

Abarca ML, Bragulat MR, Castellá G, Cabañes FJ (2019) Impact of some environmental factors on growth and ochratoxin A production by Aspergillus niger and Aspergillus welwitschiae. Int $\mathrm{J}$ Food Microbiol 291:10-16. https://doi.org/10.1016/j.ijfoodmicro.2018.11.001

Adamiak J, Bonifay V, Otlewska A, et al (2017) Untargeted metabolomics approach in halophiles: Understanding the biodeterioration process of building materials. Front Microbiol 8:1-12. https://doi.org/10.3389/fmicb.2017.02448

Akhtar MK, Dandapani H, Thiel K, Jones PR (2015) Microbial production of 1-octanol: A naturally excreted biofuel with diesel-like properties. Metab Eng Commun 2:1-5. https://doi.org/10.1016/j.meteno.2014.11.001 
Alves Z, Melo A, Figueiredo AR, et al (2015) Exploring the Saccharomyces cerevisiae Volatile Metabolome: Indigenous versus Commercial Strains. PLoS One 10:e0143641.

https://doi.org/10.1371/journal.pone.0143641

Aquino S, de Lima JEA, do Nascimento APB, Reis FC (2018) Analysis of fungal contamination in vehicle air filters and their impact as a bioaccumulator on indoor air quality. Air Qual Atmos Heal 1-11. https://doi.org/10.1088/0953-2048/20/11/S23

Baptista I, Santos M, Rudnitskaya A, et al (2019) A comprehensive look into the volatile exometabolome of enteroxic and non-enterotoxic Staphylococcus aureus strains. Int J Biochem Cell Biol 108:40-50. https://doi.org/10.1016/j.biocel.2019.01.007

Bazioli JM, Belinato JR, Costa JH, et al (2019) Biological Control of Citrus Postharvest Phytopathogens. 11:1-22. https://doi.org/10.3390/toxins11080460

Caldeira M, Barros AS, Bilelo MJ, et al (2011) Profiling allergic asthma volatile metabolic patterns using a headspace-solid phase microextraction/gas chromatography based methodology. J Chromatogr A 1218:3771-3780. https://doi.org/10.1016/j.chroma.2011.04.026

Cano A, Cháfer M, Chiralt A, González-Martínez C (2015) Physical and Antimicrobial Properties of StarchPVA Blend Films as Affected by the Incorporation of Natural Antimicrobial Agents. Foods 5:3. https://doi.org/10.3390/foods5010003

Cardoso P, Santos M, Freitas R, et al (2017) Response of Rhizobium to Cd exposure: A volatile perspective. Environ Pollut 231:802-811. https://doi.org/10.1016/j.envpol.2017.08.067

Carriço ÍR, Marques J, Trujillo-Rodriguez MJ, et al (2020) Sorbent coatings for solid-phase microextraction targeted towards the analysis of death-related polar analytes coupled to comprehensive two-dimensional gas chromatography: Comparison of zwitterionic polymeric ionic liquids versus commercial coatings. Microchem J 158:105243. https://doi.org/10.1016/j.microc.2020.105243

Costa CP, Gonçalves Silva D, Rudnitskaya A, et al (2016) Shedding light on Aspergillus Niger volatile exometabolome. Sci Rep 6:1-13. https://doi.org/10.1038/srep27441

Cubero-Leon E, Peñalver R, Maquet A (2014) Review on metabolomics for food authentication. Food Res Int 60:95-107. https://doi.org/10.1016/j.foodres.2013.11.041

Cumeras R, Aksenov AA, Pasamontes A, et al (2016) Identification of fungal metabolites from inside Gallus gallus domesticus eggshells by non-invasively detecting volatile organic compounds (VOCs). Anal Bioanal Chem 408:6649-6658. https://doi.org/10.1007/s00216-016-9778-3

Dachery B, Hernandes KC, Veras FF, et al (2019) Effect of Aspergillus carbonarius on ochratoxin a levels, volatile profile and antioxidant activity of the grapes and respective wines. Food Res Int 126:108687. https://doi.org/10.1016/j.foodres.2019.108687 
de Souza JRB, Dias FFG, Caliman JD, et al (2018a) Opportunities for green microextractions in comprehensive two-dimensional gas chromatography / mass spectrometry-based metabolomics - A review. Anal Chim Acta 1040:1-18. https://doi.org/10.1016/j.aca.2018.08.034

de Souza JRB, Kupper KC, Augusto F (2018b) In vivo investigation of the volatile metabolome of antiphytopathogenic yeast strains active against Penicillium digitatum using comprehensive twodimensional gas chromatography and multivariate data analysis. Microchem J 141:204-209. https://doi.org/10.1016/j.microc.2018.05.036

de Souza JRB, Kupper KC, Augusto F (2018c) In vivo investigation of the volatile metabolome of antiphytopathogenic yeast strains active against Penicillium digitatum using comprehensive twodimensional gas chromatography and multivariate data analysis. Microchem J 141:362-368. https://doi.org/10.1016/j.microc.2018.05.047

Erban A, Fehrle I, Martinez-Seidel F, et al (2019) Discovery of food identity markers by metabolomics and machine learning technology. Sci Rep 9:1-19. https://doi.org/10.1038/s41598-019-46113-y

Fan S, Shahid M, Jin P, et al (2020) Identification of Metabolic Alterations in Breast Cancer Using Mass Spectrometry-Based Metabolomic Analysis. Metabolites 10:170. https://doi.org/10.3390/metabo10040170

Fang S, Liu S, Song J, et al (2021) Recognition of pathogens in food matrixes based on the untargeted in vivo microbial metabolite profiling via a novel SPME/GC × GC-QTOFMS approach. Food Res Int 142:110213. https://doi.org/10.1016/j.foodres.2021.110213

Fialho MB, Toffano L, Pedroso MP, et al (2010) Volatile organic compounds produced by Saccharomyces cerevisiae inhibit the in vitro development of Guignardia citricarpa, the causal agent of citrus black spot. World J Microbiol Biotechnol 26:925-932. https://doi.org/10.1007/s11274-009-0255-4

Finger JAFF, Baroni WSGV, Maffei DF, et al (2019) Overview of foodborne disease outbreaks in Brazil from 2000 to 2018 . Foods $8: 1-10$. https://doi.org/10.3390/foods 8100434

Fonseca AMA, Dias C, Amaro AL, et al (2020) The impact of plant-based coatings in "ROCHA" pear preservation during cold storage: A metabolomic approach. Foods 9:.

https://doi.org/10.3390/foods9091299

Freire L, Braga PAC, Furtado MM, et al (2020) From grape to wine: Fate of ochratoxin A during red, rose, and white winemaking process and the presence of ochratoxin derivatives in the final products. Food Control 113:. https://doi.org/10.1016/j.foodcont.2020.107167

Freire L, Guerreiro TM, Pia AKR, et al (2018a) A quantitative study on growth variability and production of ochratoxin A and its derivatives by A. carbonarius and A. niger in grape-based medium. Sci Rep 8:14573. https://doi.org/10.1038/s41598-018-32907-z 
Freire L, Guerreiro TM, Pia AKR, et al (2018b) A quantitative study on growth variability and production of ochratoxin A and its derivatives by A. carbonarius and A. niger in grape-based medium. Sci Rep 8:1-11. https://doi.org/10.1038/s41598-018-32907-z

Gajera HP, Katakpara ZA, Patel S V., Golakiya BA (2016) Antioxidant defense response induced by Trichoderma viride against Aspergillus niger Van Tieghem causing collar rot in groundnut (Arachis hypogaea L.). Microb Pathog 91:26-34. https://doi.org/10.1016/j.micpath.2015.11.010

Gil-Serna J, García-Díaz M, Vázquez C, et al (2019) Significance of Aspergillus niger aggregate species as contaminants of food products in Spain regarding their occurrence and their ability to produce mycotoxins. Food Microbiol 82:240-248. https://doi.org/10.1016/j.fm.2019.02.013

Gómez J V., Tarazona A, Mateo F, et al (2019) Potential impact of engineered silver nanoparticles in the control of aflatoxins, ochratoxin A and the main aflatoxigenic and ochratoxigenic species affecting foods. Food Control 101:58-68. https://doi.org/10.1016/j.foodcont.2019.02.019

Hazelwood LA, Daran JM, Van Maris AJA, et al (2008) The Ehrlich pathway for fusel alcohol production: A century of research on Saccharomyces cerevisiae metabolism. Appl Environ Microbiol 74:2259-2266. https://doi.org/10.1128/AEM.02625-07

Ho J, Prosser R, Hasani M, et al (2020) Degradation of chlorpyrifos and inactivation of Escherichia coli 0157:H7 and Aspergillus niger on apples using an advanced oxidation process. Food Control 109:. https://doi.org/10.1016/j.foodcont.2019.106920

Järvinen AK, Laakso S, Piiparinen P, et al (2009) Rapid identification of bacterial pathogens using a PCRand microarray-based assay. BMC Microbiol 9:. https://doi.org/10.1186/1471-2180-9-161

Jedidi I, Cruz A, González-Jaén MT, Said S (2017) Aflatoxins and ochratoxin A and their Aspergillus causal species in Tunisian cereals. Food Addit Contam Part B Surveill 10:51-58.

https://doi.org/10.1080/19393210.2016.1247917

Kumar P, Mishra S, Kumar A, et al (2017) In vivo and in vitro control activity of plant essential oils against three strains of Aspergillus niger. Environ Sci Pollut Res 24:21948-21959. https://doi.org/10.1007/s11356017-9730-x

LI F xiang, LI F hua, YANG Y xuan, et al (2019) Comparison of phenolic profiles and antioxidant activities in skins and pulps of eleven grape cultivars (Vitis vinifera L.). J Integr Agric 18:1148-1158. https://doi.org/10.1016/S2095-3119(18)62138-0

Li Q, Li C, Li P, et al (2017) The biocontrol effect of Sporidiobolus pararoseus Y16 against postharvest diseases in table grapes caused by Aspergillus niger and the possible mechanisms involved. Biol Control 113:18-25. https://doi.org/10.1016/j.biocontrol.2017.06.009 
Li S, Hu Y, Liu W, et al (2020) Untargeted volatile metabolomics using comprehensive two-dimensional gas chromatography-mass spectrometry - A solution for orange juice authentication. Talanta 217:121038. https://doi.org/10.1016/j.talanta.2020.121038

Liu Y, Xu XL, Zhou GH (2007) Comparative study of volatile compounds in traditional Chinese Nanjing marinated duck by different extraction techniques. Int J Food Sci Technol 42:543-550. https://doi.org/10.1111/j.1365-2621.2006.01264.x

Loureiro CC, Duarte IF, Gomes J, et al (2014) Urinary metabolomic changes as a predictive biomarker of asthma exacerbation. J Allergy Clin Immunol 133:. https://doi.org/10.1016/j.jaci.2013.11.004

Martins C, Brandão T, Almeida A, Rocha SM (2017) Metabolomics strategy for the mapping of volatile exometabolome from Saccharomyces spp. widely used in the food industry based on comprehensive twodimensional gas chromatography. J Sep Sci 40:2228-2237. https://doi.org/10.1002/jssc.201601296

Martins C, Brandão T, Almeida A, Rocha SM (2020) Enlarging knowledge on lager beer volatile metabolites using multidimensional gas chromatography. Foods 9:1-22. https://doi.org/10.3390/foods 9091276

Masuo S, Osada L, Zhou S, et al (2015) Aspergillus oryzae pathways that convert phenylalanine into the flavor volatile 2-phenylethanol. Fungal Genet Biol 77:22-30. https://doi.org/10.1016/j.fgb.2015.03.002

Matos D, Sá C, Cardoso P, et al (2019) The role of volatiles in Rhizobium tolerance to cadmium: Effects of aldehydes and alcohols on growth and biochemical endpoints. Ecotoxicol Environ Saf 186:109759. https://doi.org/10.1016/j.ecoenv.2019.109759

Mousavi F, Bojko B, Bessonneau V, Pawliszyn J (2016) Cinnamaldehyde Characterization as an Antibacterial Agent toward E. coli Metabolic Profile Using 96-Blade Solid-Phase Microextraction Coupled to Liquid Chromatography-Mass Spectrometry. J Proteome Res 15:963-975.

https://doi.org/10.1021/acs.jproteome.5b00992

Oliveira DR, Leitão GG, Santos SS, et al (2006) Ethnopharmacological study of two Lippia species from Oriximiná, Brazil. J Ethnopharmacol 108:103-108. https://doi.org/10.1016/j.jep.2006.04.018

Pan X, Liu H, Liu J, et al (2016) Omics-based approaches reveal phospholipids remodeling of Rhizopus oryzae responding to furfural stress for fumaric acid-production from xylose. Bioresour Technol 222:2432. https://doi.org/10.1016/j.biortech.2016.09.101

Pantoja LDM, do Nascimento RF, de Araujo Nunes AB (2016) Investigation of fungal volatile organic compounds in hospital air. Atmos Pollut Res 7:659-663. https://doi.org/10.1016/j.apr.2016.02.011

Parastar H, Garreta-Lara E, Campos B, et al (2018) Chemometrics comparison of gas chromatography with mass spectrometry and comprehensive two-dimensional gas chromatography with time-of-flight mass spectrometry Daphnia magna metabolic profiles exposed to salinity. J Sep Sci 41:2368-2379. https://doi.org/10.1002/jssc.201701336 
Poole P (2017) Shining a light on the dark world of plant root-microbe interactions. Proc Natl Acad Sci 114:4281-4283. https://doi.org/10.1073/pnas.1703800114

Rees CA, Burklund A, Stefanuto PH, et al (2018) Comprehensive volatile metabolic fingerprinting of bacterial and fungal pathogen groups. J Breath Res 12:. https://doi.org/10.1088/1752-7163/aa8f7f

Rees CA, Franchina FA, Nordick K V., et al (2017) Expanding the Klebsiella pneumoniae volatile metabolome using advanced analytical instrumentation for the detection of novel metabolites. J Appl Microbiol 122:785-795. https://doi.org/10.1111/jam.13372

Risticevic S, Souza-Silva EA, Gionfriddo E, et al (2020) Application of in vivo solid phase microextraction (SPME) in capturing metabolome of apple (Malus ×domestica Borkh.) fruit. Sci Rep 10:1-11. https://doi.org/10.1038/s41598-020-63817-8

Rocha SM, Caldeira M, Carrola J, et al (2012) Exploring the human urine metabolomic potentialities by comprehensive two-dimensional gas chromatography coupled to time of flight mass spectrometry. $J$ Chromatogr A 1252:155-163. https://doi.org/10.1016/j.chroma.2012.06.067

Rocha SM, Freitas R, Cardoso P, et al (2013) Exploring the potentialities of comprehensive two-dimensional gas chromatography coupled to time of flight mass spectrometry to distinguish bivalve species:

Comparison of two clam species (Venerupis decussata and Venerupis philippinarum). J Chromatogr A 1315:152-161. https://doi.org/10.1016/j.chroma.2013.09.049

Salvador ÂC, Baptista I, Barros AS, et al (2013) Can Volatile Organic Metabolites Be Used to Simultaneously Assess Microbial and Mite Contamination Level in Cereal Grains and Coffee Beans? PLoS One 8:e59338. https://doi.org/10.1371/journal.pone.0059338

Santos-Ciscon BA dos, van Diepeningen A, Machado J da C, et al (2019) Aspergillus species from Brazilian dry beans and their toxigenic potential. Int J Food Microbiol 292:91-100.

https://doi.org/10.1016/j.ijfoodmicro.2018.12.006

Sarrocco S, Vannacci G (2018) Preharvest application of beneficial fungi as a strategy to prevent postharvest mycotoxin contamination: A review. Crop Prot 110:160-170.

https://doi.org/10.1016/j.cropro.2017.11.013

Schloter M, Abmus B, Hartmann A (1995) The Use of Immunological Methods To Detect and Identify Bacteria in the Environment. Biotech Adv 13:75-90

Schueuermann C, Steel CC, Blackman JW, et al (2019) A GC-MS untargeted metabolomics approach for the classification of chemical differences in grape juices based on fungal pathogen. Food Chem 270:375384. https://doi.org/10.1016/j.foodchem.2018.07.057

Silva I, Rocha SM, Coimbra MA, Marriott PJ (2010) Headspace solid-phase microextraction combined with comprehensive two-dimensional gas chromatography time-of-flight mass spectrometry for the 
determination of volatile compounds from marine salt. J Chromatogr A 1217:5511-5521. https://doi.org/10.1016/j.chroma.2010.06.050

Souza-Silva ÉA, Reyes-Garcés N, Gómez-Ríos GA, et al (2015) A critical review of the state of the art of solid-phase microextraction of complex matrices III. Bioanalytical and clinical applications. TrAC - Trends Anal Chem 71:249-264. https://doi.org/10.1016/j.trac.2015.04.017

Sumner LW, Amberg A, Barrett D, et al (2007) Proposed minimum reporting standards for chemical analysis: Chemical Analysis Working Group (CAWG) Metabolomics Standards Initiative (MSI). Metabolomics 3:211-221. https://doi.org/10.1007/s11306-007-0082-2

Sun Q, Li J, Sun Y, et al (2020) The antifungal effects of cinnamaldehyde against Aspergillus niger and its application in bread preservation. Food Chem 317:126405.

https://doi.org/10.1016/j.foodchem.2020.126405

Tong H, Wang Y, Li Y, et al (2017) Volatile organic metabolites identify patients with gastric carcinoma, gastric ulcer, or gastritis and control patients. Cancer Cell Int 17:1-9. https://doi.org/10.1186/s12935-0170475-x

Triba MN, Le Moyec L, Amathieu R, et al (2015) PLS/OPLS models in metabolomics: The impact of permutation of dataset rows on the K-fold cross-validation quality parameters. Mol Biosyst 11:13-19. https://doi.org/10.1039/c4mb00414k

van Den Dool H, Dec. Kratz P (1963) A generalization of the retention index system including linear temperature programmed gas-liquid partition chromatography. J Chromatogr A 11:463-471. https://doi.org/10.1016/S0021-9673(01)80947-X

Wang L, Meeus I, Rombouts C, et al (2019) Metabolomics-based biomarker discovery for bee health monitoring: A proof of concept study concerning nutritional stress in Bombus terrestris. Sci Rep 9:1-11. https://doi.org/10.1038/s41598-019-47896-w

Weldegergis BT, Crouch AM, Górecki T, de Villiers A (2011) Solid phase extraction in combination with comprehensive two-dimensional gas chromatography coupled to time-of-flight mass spectrometry for the detailed investigation of volatiles in South African red wines. Anal Chim Acta 701:98-111. https://doi.org/10.1016/j.aca.2011.06.006

Xanthopoulou A, Ganopoulos I, Tryfinopoulou P, et al (2019) Rapid and accurate identification of black aspergilli from grapes using high-resolution melting (HRM) analysis. J Sci Food Agric 99:309-314. https://doi.org/10.1002/jsfa.9189

Xanthopoulou A, Ganopoulos I, Tryfinopoulou P, et al (2018) Rapid and accurate identification of black aspergilli from grapes using high-resolution melting (HRM) analysis. J Sci Food Agric.

https://doi.org/10.1002/jsfa.9189 
Xu X, Van Stee LLP, Williams J, et al (2003) Comprehensive two-dimensional gas chromatography (GC×GC) measurements of volatile organic compounds in the atmosphere. Atmos Chem Phys 3:665-682. https://doi.org/10.5194/acp-3-665-2003

Zhang QH, Zhou L Di, Chen H, et al (2016) Solid-phase microextraction technology for in vitro and in vivo metabolite analysis. TrAC - Trends Anal Chem 80:57-65. https://doi.org/10.1016/j.trac.2016.02.017

Zhang XW, Li QH, Xu Z Di, Dou JJ (2020) Mass spectrometry-based metabolomics in health and medical science: A systematic review. RSC Adv 10:3092-3104. https://doi.org/10.1039/c9ra08985c

Zhao C, Li X, Liang Y, et al (2006) Comparative analysis of chemical components of essential oils from different samples of Rhododendron with the help of chemometrics methods. Chemom Intell Lab Syst 82:218-228. https://doi.org/10.1016/j.chemolab.2005.08.008

Zhao G, Yin G, Inamdar AA, et al (2017) Volatile organic compounds emitted by filamentous fungi isolated from flooded homes after Hurricane Sandy show toxicity in a Drosophila bioassay. Indoor Air 27:518-528. https://doi.org/10.1111/ina.12350

\section{Figures}

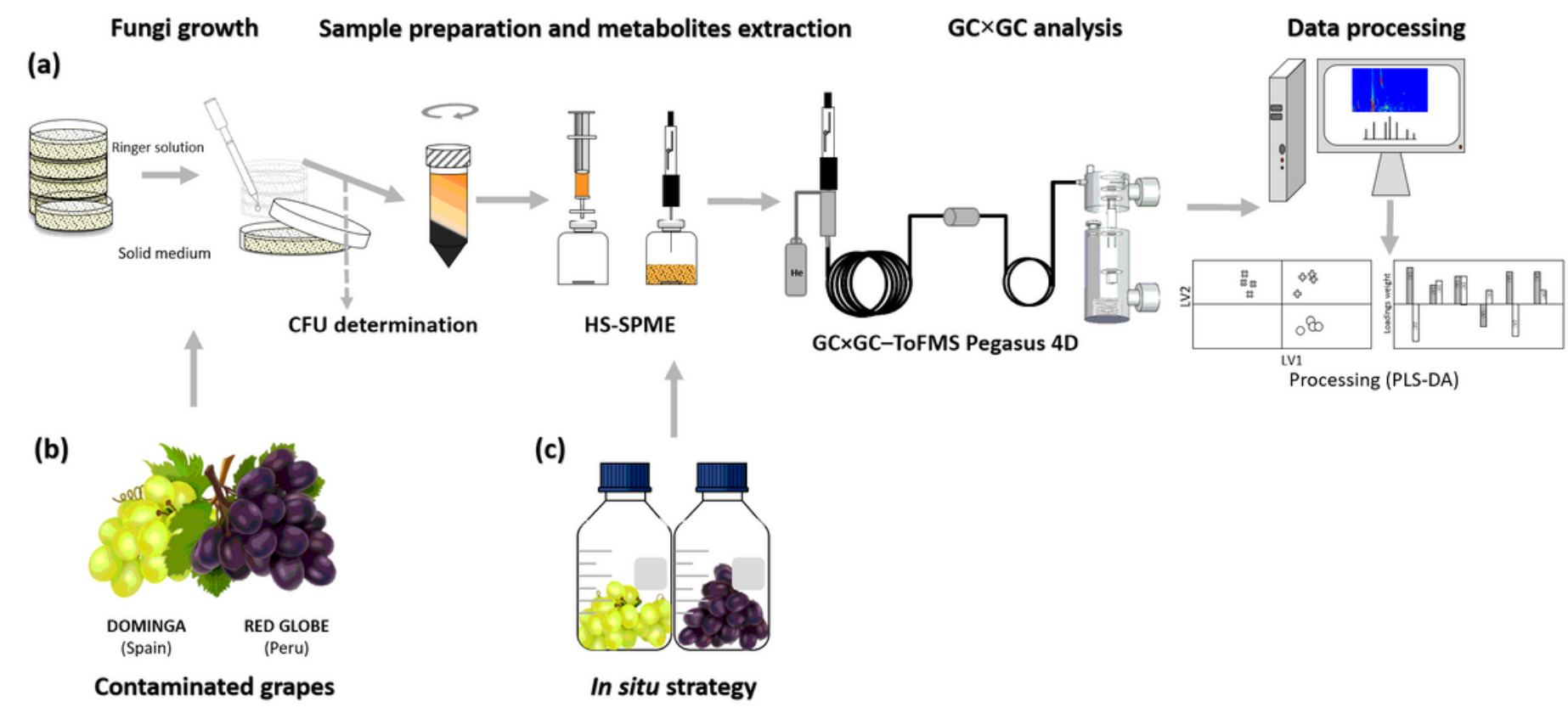

Figure 1

Sample preparation protocol for the three main strategies adopted in this study: (a) evaluation of the volatile exometaboloma from A. niger pattern previous reported using 1 day of growth of A. niger cultures (Costa et al. 2016) (b) analysis of A. niger cultures obtained from previously contaminated grapes and (c) direct analysis of contaminated table grapes with A. niger (in situ analysis). 

(a) $Y G C_{A}$
(b) A. niger -1 day of growth
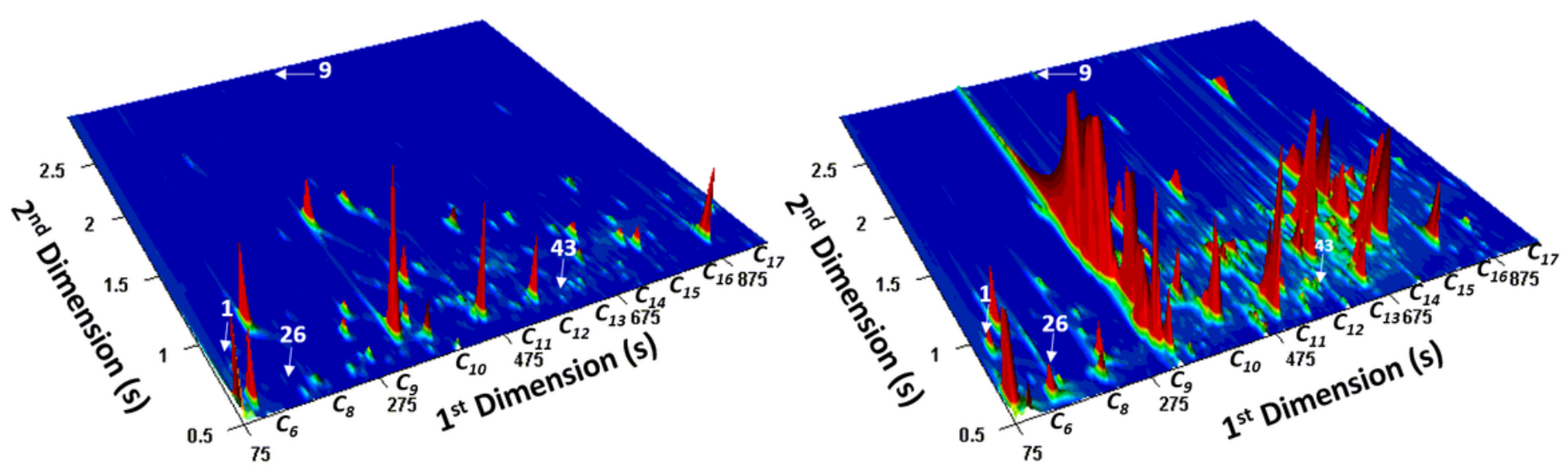

(c) 2-Phenylethanol

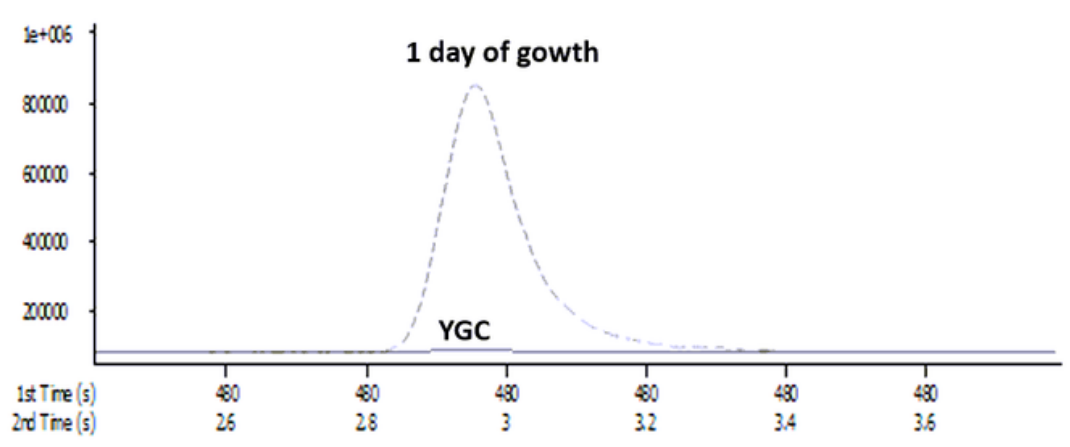

Figure 2

GC $\times$ GC-ToFMS total ion chromatogram contour plot of the VOCs released from: a) Yeast Glucose Chloramphenicol Agar medium (YGCA), used as control and b) A. niger culture headspace volatile components inoculated in YGCA, for 1 day of growth, at $37^{\circ} \mathrm{C}$. c) The wide 2-phenylethanol GC $\times$ GC peak was identified at a mass spectral acquisition of 100 spectra/s for 1 day of growth and absent for the YGCA. Peak number assignment in Table S1. 


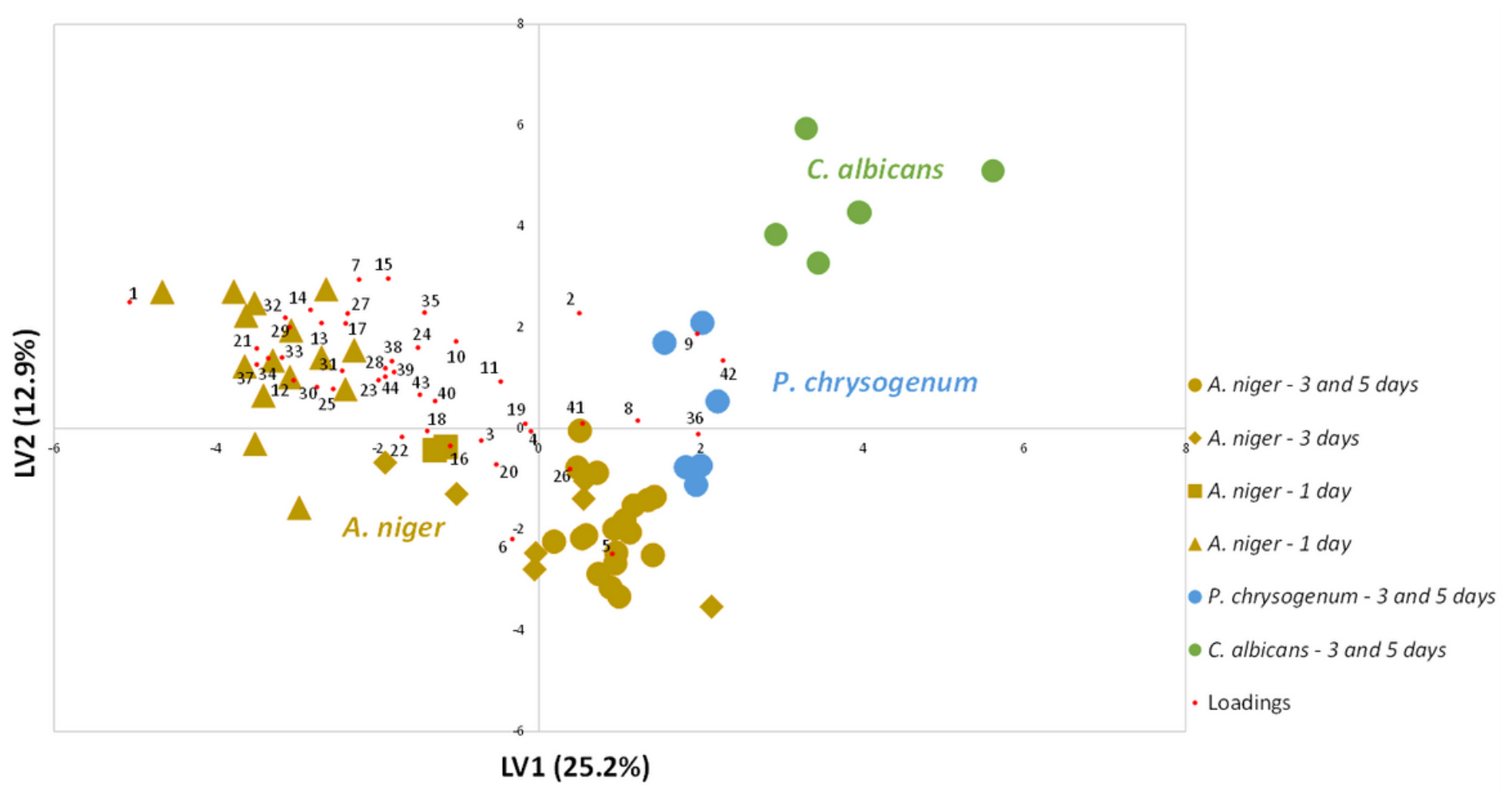

Figure 3

PLS-DA biplot of the samples (LV1×LV2) using the 44 metabolites sub-data set from the full data set presented in Table S1 (gray-highlighted) identified by HS-SPME/GC×GC-ToFMS with the areas previously standardized by CFU mL-1. Results obtained by performing the pure culture growth in solid YGCA culture medium and using different growth times.

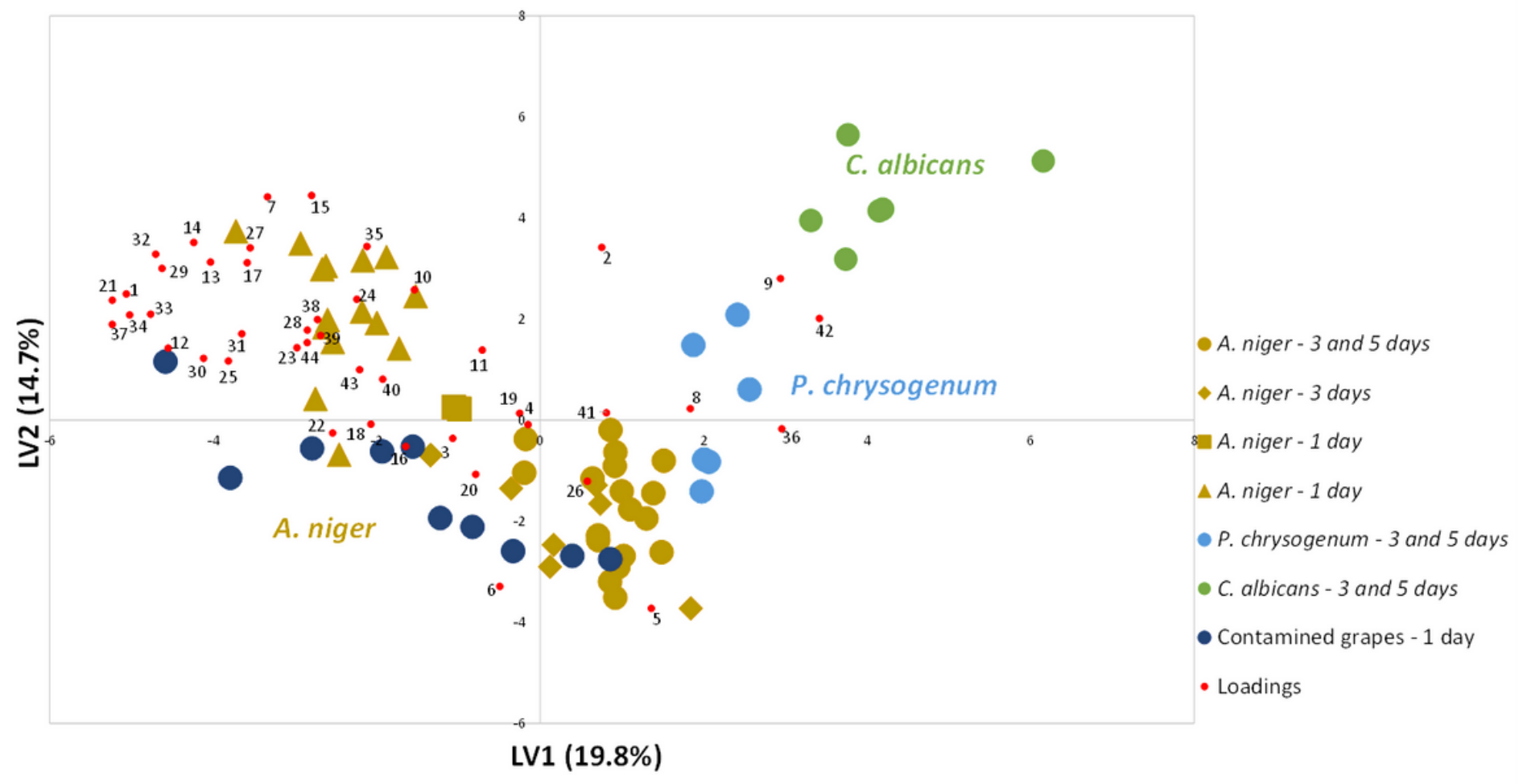

Figure 4 
PLS-DA biplot of samples (LV1 $\times$ LV2) using the full data set of 44 metabolites identified by HSSPME/GC×GC-ToFMS with the areas previously standardized by CFU mL-1 (Table S1). Results obtained by performing the pure culture growth in solid YGCA culture medium and by contaminated grapes (Red Globe and Dominga) with A. niger.

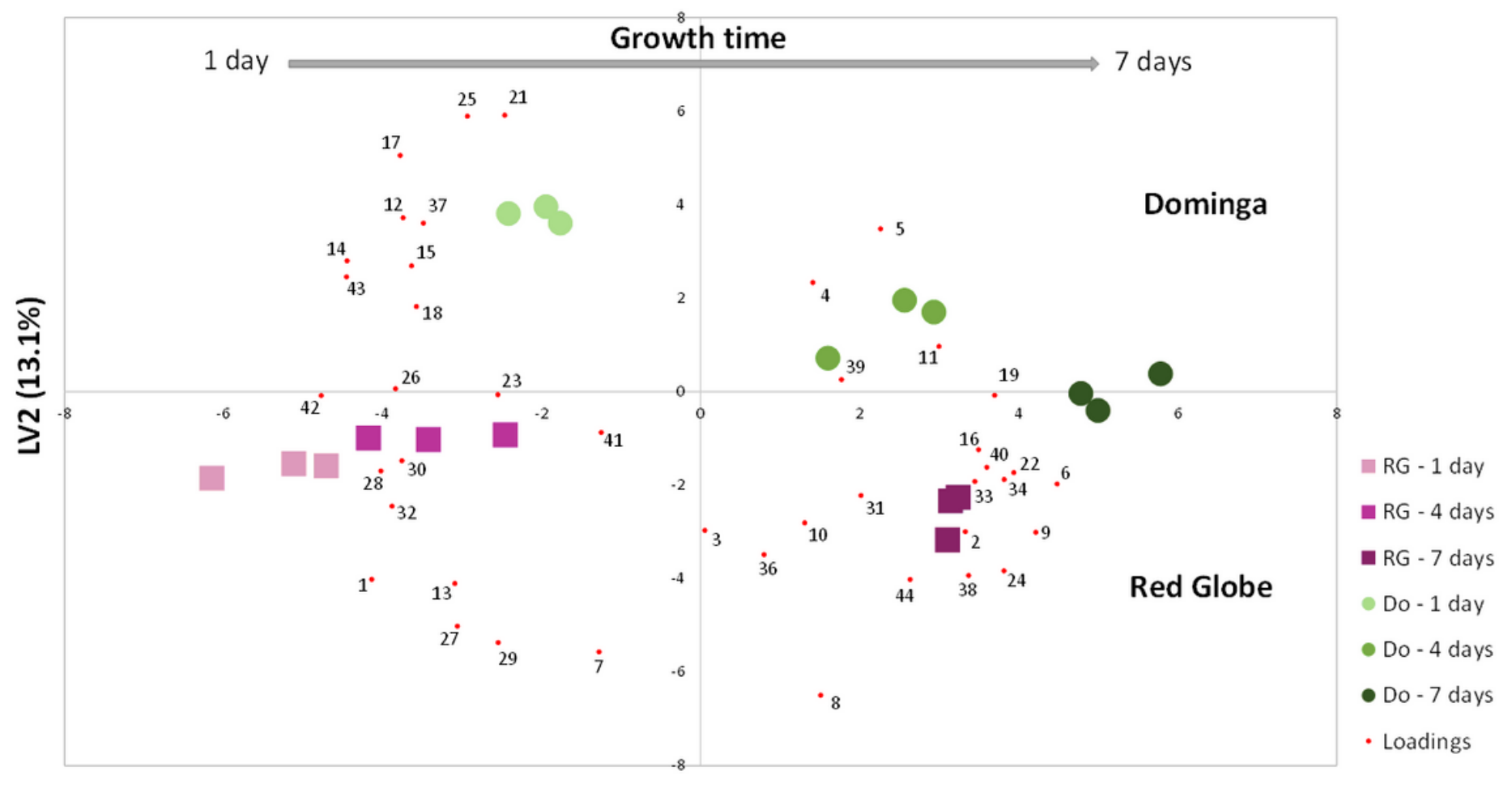

LV1 (41.1\%)

Figure 5

PLS-DA biplot of samples (LV1 $\times$ LV2) using the full data set of 42 metabolites identified by HSSPME/GC×GC-ToFMS for White (Do) and Red (RG) grapes over 7 days (Table S2).

\section{Supplementary Files}

This is a list of supplementary files associated with this preprint. Click to download.

- GraphicalAbstract.tif

- SupplementaryInformationFigureS1.docx

- SupplementaryInformationTablesS1andS2.xls 